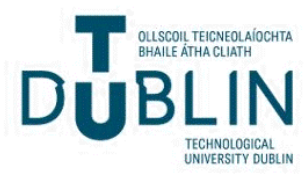

Technological University Dublin

ARROW@TU Dublin

\section{Evaluation of plasma, high-pressure and ultrasound processing on the stability of fructooligosaccharides}

\author{
Elenilson Alves Filho \\ Universidade Federal do Ceara \\ Patrick J. Cullen \\ Technological University Dublin, patrick.j.cullen@tudublin.ie \\ Jesus Maria Frias \\ Technological University Dublin, Jesus.Frias@tudublin.ie
}

See next page for additional authors

Follow this and additional works at: https://arrow.tudublin.ie/schfsehart

Part of the Food Science Commons

\section{Recommended Citation}

Alves Filho, E.G., Cullen, P.J., Frias, J.M., Bourke, P., Tiwari, B.K., Brito, E.S., Rodrigues, S. and Fernandes, F.A. (2016), Evaluation of plasma, high-pressure and ultrasound processing on the stability of fructooligosaccharides. Int J Food Sci Technol, 51: 2034-2040. DOI: 10.1111/ijfs.13175

This Article is brought to you for free and open access by the School of Food Science and Environmental Health at ARROW@TU Dublin. It has been accepted for inclusion in Articles by an authorized administrator of ARROW@TU

Dublin. For more information, please contact

arrow.admin@tudublin.ie, aisling.coyne@tudublin.ie, gerard.connolly@tudublin.ie.

Funder: CNPq; FUNCAP

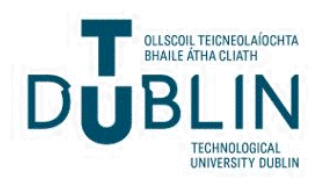




\section{Authors}

Elenilson Alves Filho, Patrick J. Cullen, Jesus Maria Frias, Paula Bourke, Brijesh Tiwari, Edy Brito, Sueli Rodrigues, and Fabiano Fernandes 


\title{
Evaluation of plasma, high-pressure and ultrasound processing on the stability of fructooligosaccharides
}

\author{
Elenilson G. Alves Filho, ${ }^{1,2}$ Patrick J. Cullen, ${ }^{3,4}$ Jesus M. Frias, ${ }^{3}$ Paula Bourke, ${ }^{3}$ Brijesh K. Tiwari, ${ }^{5}$ Edy S. Brito, ${ }^{2}$ \\ Sueli Rodrigues ${ }^{1}$ \& Fabiano A.N. Fernandes ${ }^{6 *}$ \\ 1 Departamento de Tecnologia de Alimentos, Universidade Federal do Ceará, Campus do Pici, Bloco 858, 60440-900, Fortaleza, CE, Brazil \\ 2 Embrapa Agroindustria Tropical, Fortaleza, CE, Brazil \\ 3 Dublin Institute of Technology, School of Food Science and Environmental Health, Dublin, UK \\ 4 School of Chemical Engineering, University of New South Wales, Sydney, NSW, Australia \\ 5 Teagasc Food Research Centre, Department of Food Biosciences, Dublin, UK \\ 6 Universidade Federal do Ceará, Departamento de Engenharia Química, Campus do Pici, Bloco 709, 60440-900 Fortaleza, CE, Brazil
}

\section{(Received 7 April 2016; Accepted in revised form 24 May 2016)}

Summary Fructooligosaccharides (FOS) are among the main carbohydrates with prebiotic activity, and they are the most applied functional carbohydrate ingredient in the food industry. FOS are known to hydrolyse when subjected to thermal processing, thus partially losing its functional properties. In this study, we evaluate whether three nonthermal technologies are suitable for processing FOS regarding its stability after processing. FOS were subjected to ultrasound, high-pressure processing (HPP) and atmospheric cold plasma (ACP). The FOS solution, $70 \mathrm{~g} \mathrm{~L}^{-1}$, was set at a concentration recommended for human intake. The treatments were carried out at operating conditions usually used for microbial inactivation in foods (HPP at $450 \mathrm{MPa}$ for $5 \mathrm{~min}$; US at $600-1200 \mathrm{~W} \mathrm{~L}^{-1}$ for $5 \mathrm{~min}$; ACP at $70 \mathrm{kV}$ for $15-60 \mathrm{~s}$ ). NMR and HPLC analysis of the FOS components showed that ACP, ultrasound and HPP have not induced any significant change on FOS concentration $(<2.0 \%)$ nor on the degree of polymerisation of the FOS $(<3.3 \%)$. Contrarily to what is reported for thermal treatments, these nonthermal technologies were considered suitable for FOS processing.

Keywords Fructooligosaccharides, functional carbohydrates, high-pressure processing, NMR, nonthermal technology.

\section{Introduction}

Supplementation of beverages and foods with nutraceutical components improves their nutritional quality (Breithaupt, 2001; Renuka et al., 2009). Fortification with probiotics or with prebiotics is a recent trend in this market, and several new products have been developed and marketed in the past few years (Luckow et al., 2006). Prebiotics like fructooligosaccharides (FOS) have attracted special attention because of their nutraceutical properties and because they have a sweet taste similar to sucrose (Yun, 1996). FOS have been incorporated in several food products because they are easier to add into some foods than other probiotics (Macfarlane et al., 2006; Ranadheera et al., 2010).

Fructooligosaccharides are fructose oligomers consisting of a chain of fructosyl moieties linked by a $\beta$ (2-1)-glycosidic bond, which is linked by an $\alpha$ (1-2)-

*Correspondent: Fax: +558533669610; e-mail: fabiano@ufc.br glycosidic bond to a single glucose unit at the nonreducing end (L'Homme et al., 2003a,b). The number of fructosyl moieties ranges between 3 and 8 . FOS act as a functional food ingredient, regulate the growth of beneficial bifidobacteria in the digestive tract, reduce total cholesterol and provide a general improvement in human health (Tomomatsu, 1994; Rastall, 2010; Morris \& Morris, 2012; Saad et al., 2013).

One of the main problems when incorporating FOS into food products is that most processes, including pasteurisation and/or sterilisation, trigger the chemical hydrolysis of these components (L'Homme et al., 2003a,b; Courtin et al., 2009). FOS hydrolyse at low $\mathrm{pH}$ and mild temperatures, which are conditions easily achieved during processing and long-term storage (Charalampopoulos \& Rastall, 2012). Studies with FOS decomposition showed a first-order kinetic rate for the hydrolysis of FOS and sucrose, but with a much lower activation energy for FOS than for sucrose, indicating that less energy is required to hydrolyse FOS (L'Homme et al., 2003a,b). Studies 
have also shown that the kinetic rate decreased with the chain length (Aguilar et al., 2002; Vega \& ZunigaHansen, 2015). The degree of degradation of FOS during thermal processing depends on the temperature applied and the $\mathrm{pH}$ of the solution or food matrix.

Nonthermal processes, such as atmospheric cold plasma, high-pressure processing and ultrasound processing, have been shown as potential substitutes to thermal processes and are being applied in some applications in the food industry. Several studies showed that these nonthermal processes have positive impact on the nutritional and sensory quality of many food products (Denes, 2004; Perera et al., 2009; Fernandes et al., 2010; Garcia-Noguera et al., 2010; Costa et al., 2011). These nonthermal processes could prevent the hydrolysis of FOS because of the milder operating conditions that are applied.

In this work, the influence of three nonthermal processes was evaluated on the stability of FOS. Plasma processing, high-pressure processing and ultrasound processing followed by high-pressure processing were applied to an aqueous FOS solution, and the retention of FOS was evaluated. A model solution was used to evaluate the direct effect of these processes on FOS hydrolysis.

\section{Materials and methods}

\section{Materials and sample preparation}

Commercial fructooligosaccharides (FOS) (Orafti P95) were donated by Beneo GmbH (Mannheim, Germany) and consisted of FOS with five different degrees of polymerisation (DP). The samples subjected to plasma, ultrasound and high-pressure processing (HPP) were prepared diluting FOS into distilled water obtaining a solution of $70 \mathrm{~g} \mathrm{~L}^{-1}$. This concentration of FOS was set taking into account the recommended human intake reported by some authors (Alles et al., 1999; Carabin \& Flamm, 1999; Al-Sheraji et al., 2013) and considers a daily intake of up to $500 \mathrm{~mL}$ of FOS containing products. Up to this date (May/2016), there is no official recommended human intake set by agencies such as FAO, FDA or others.

The concentrations of FOS, fructose and glucose of the untreated FOS solution were: $3.1 \pm 0.1$ of fructose, $4.2 \pm 0.1$ of glucose, $14.2 \pm 0.1$ of DP3, $14.2 \pm 0.1$ of DP4, $31.0 \pm 0.1$ of DP5, $3.3 \pm 0.1$ of FOS with higher degrees of polymerisation (which will be denoted as DP5 + ).

\section{Sample processing}

Plasma processing was carried out applying atmospheric cold plasma (ACP) to the samples at four different processing times $(15,30,45$ and $60 \mathrm{~s})$ and in two different positions concerning the plasma beam: direct plasma exposure (IN) and indirect plasma exposure (OUT). Before applying ACP, $20 \mathrm{~mL}$ of the FOS solution was placed in Petri dishes of $50 \mathrm{~mm}$ of diameter and were packaged inside polyethylene terephthalate (PET) trays. The experiments were carried out at a discrete voltage of $70 \mathrm{kV}$ using ambient air at atmospheric pressure conditions. Full description of the experimental apparatus can be found in Segat et al. (2015). The treatment time was selected based on a previous study carried for pathogens inactivation. As reported by Ziuzina et al. (2015), complete bacterial inactivation was achieved after $20 \mathrm{~s}$ of direct exposure and $45 \mathrm{~s}$ of indirect exposure.

High-pressure processing was carried out in an industrial hydrostatic unit (Hiperbaric 420) at HPP Tolling Ltd (Dublin, Ireland). The samples were conditioned in transparent polyethylene flasks of $250 \mathrm{~mL}$ and subjected to high-pressure processing at $450 \mathrm{MPa}$ for $300 \mathrm{~s}$, with water at $7{ }^{\circ} \mathrm{C}$ as the pressure-transmitting medium. The time taken to reach the target pressure was $180 \mathrm{~s}$ and decompression took $15 \mathrm{~s}$. This condition was chosen because it is the condition most used in the industry and because it has been known to be effective against microorganisms (Uckoo et al., 2013; Chen et al., 2015).

Ultrasound was applied to the FOS solution using a probe ultrasound (Branson 500, Emerson Technologies GmbH, Dietzenbach, Germany). Two ultrasound power densities were applied to $250 \mathrm{~mL}$ of solution: 600 and $1200 \mathrm{~W} \mathrm{~L}^{-1}$. Ultrasound processing was carried out for $5 \mathrm{~min}$. After ultrasound application, the FOS solution was further processed by HPP applying the same conditions described previously. The use of ultrasound followed by HPP processing was carried out because ultrasound alone is not very efficient in inactivating microorganisms, but HPP can enhance the inactivation of some microorganisms and spores (Evelyn \& Silva, 2016).

All experiments were carried out in triplicate, and all analysis was performed in triplicate. Results are presented as mean and standard deviations.

\section{HPLC analysis and quantification}

High-performance liquid chromatography (HPLC) was performed in a Shimadzu prominence $20 \mathrm{AB}$ equipment to quantify the FOS in water after plasma, ultrasound and HPP treatments. The samples were filtered through a Teflon ${ }^{\mathrm{TM}}$ filter $(0.45 \mu \mathrm{m})$ to remove fine particulates, and then, $1.0 \mathrm{~mL}$ of the filtrate was transferred to vials for HPLC analysis.

The chromatographic separation was performed using a Supelco ${ }^{\mathrm{TM}}$ sulfonated polystyrene/divinylbenzene column resin in calcium form $(300 \times 7.8 \mathrm{~mm}$ I.D.). The detector employed was a refractive index (RI-10A) detector. The injection volume was $20 \mu \mathrm{L}$ in 
isocratic elution $\left(100 \%\right.$ of $\left.\mathrm{H}_{2} \mathrm{O}\right)$ for $30 \mathrm{~min}$ at $80{ }^{\circ} \mathrm{C}$ and $0.5 \mathrm{~mL} \mathrm{~min}^{-1}$ followed by 5 min of cleaning step.

Peaks were identified based on the retention times (tr), compared with standards. The standard curve for kestose, nystose, fructofuranosyl-nystose, fructose and sucrose was built over a concentration range of 40.3 to $100.2 \mathrm{mg} \mathrm{L}^{-1}$ ( $R^{2}$ value of 0.998$)$.

The combined uncertainty of the method was estimated from the standard deviation of the chromatogram integration from the duplicate analyses, pipette and balance errors.

\section{NMR analysis}

The NMR experiments were performed in an Agilent $600-\mathrm{MHz}$ spectrometer equipped with a $5 \mathrm{~mm}$ (H$\left.\mathrm{F} /{ }^{15} \mathrm{~N}^{31} \mathrm{P}\right)$ inverse detection One Probe ${ }^{\mathrm{TM}}$ with actively shielded $\mathrm{Z}$ gradient. The ${ }^{1} \mathrm{H}$ NMR spectra were performed using the PRESAT pulse sequence for nondeuterated water suppression $(\delta$ 4.85). The data were acquired with the RF pulse (p1) calibrated and 16 scans, $64 \mathrm{k}$ of time domain points for a spectral window of $16 \mathrm{ppm}$, acquisition time of $3.3 \mathrm{~s}$ and a relaxation delay of $2.0 \mathrm{~s}$. The spectra were calibrated externally to the TMSP-d4 resonance $(\delta 0.0)$ and temperature controlled to $298 \mathrm{~K}$.

One-bond ${ }^{1} \mathrm{H}^{-13} \mathrm{C}$ HSQC NMR experiments were acquired using the standard spectrometer library pulse sequences, with an evolution delay of $1.7 \mathrm{~ms}$ for an average ${ }^{1} J(\mathrm{C}, \mathrm{H})$ of $146 \mathrm{~Hz}, 1442 \times 200$ data matrix, 96 scans per t1 increment, spectral widths of 9615.4 Hz in $\mathrm{f} 2$ and $30165.9 \mathrm{~Hz}$ in $\mathrm{f} 1$ and relaxation delay of $1.0 \mathrm{~s}$.

\section{Results and discussion}

The aqueous FOS solutions were processed by atmospheric cold plasma, HPP and combined ultrasound and HPP. The ${ }^{1} \mathrm{H}_{-}{ }^{13} \mathrm{C}$ HSQC NMR spectra of the untreated FOS solution (standard) and of all treated samples were similar. Figure 1 presents the spectra of the standard FOS solution. Figures 2 and 3 present the spectra of the solution after $60 \mathrm{~s}$ under direct cold air plasma treatment and after $5 \mathrm{~min}$ subjected to
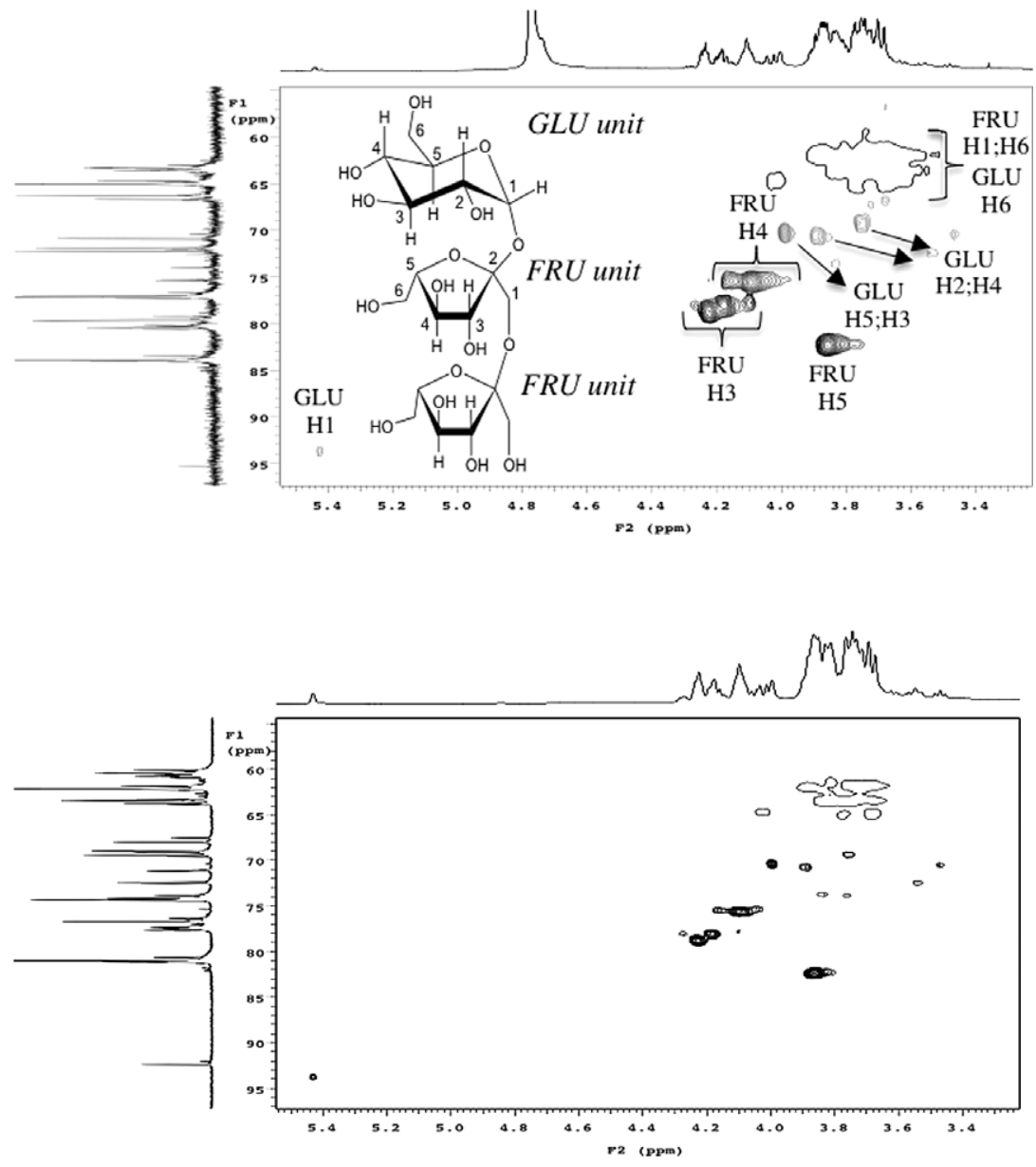

Figure 1 HSQC NMR spectra of the FOS standard solution $\left(70 \mathrm{~g} \mathrm{~L}^{-1}\right)$.

Figure 2 HSQC NMR spectra of the FOS standard solution after direct plasma treatment (70 kV for $60 \mathrm{~s})$. 
Figure 3 HSQC NMR spectra of the FOS solution after ultrasound $(1200 \mathrm{~W} / \mathrm{L}$ for $5 \mathrm{~min}$ ) followed by high-pressure processing (450 MPa for $5 \mathrm{~min}$ ).

ultrasound $\left(1200 \mathrm{~W} \mathrm{~L}^{-1}\right)$ followed by HPP treatment, which can be considered the most drastic treatments and that could theoretically infer in the highest changes in the FOS.

It could be concluded that the plasma, HPP and ultrasound processes did not change the FOS composition and did not result in any kind of depolymerisation by hydrolysis of the FOS. Analysing the results from the ${ }^{1} \mathrm{H}^{13} \mathrm{C}$ HSQC NMR spectra, none of the processes and none of the different process conditions that were tested were able to hydrolyse the FOS in aqueous solution $(P<0.05)$.

The samples were also submitted to HPLC analysis because the RID detector in HPLC has a much higher sensibility then NMR spectrometry. The analysis by this second methodology was carried out to whether confirm the results obtained by NMR analysis or to detect any change in FOS that the NMR could not detect.

The data obtained from the HPLC analysis were used to quantify the FOS, fructose and glucose in the aqueous solutions. The concentrations of kestose (DP3), nystose (DP4), fructofuranosyl-nystose (DP5), higher FOS (DP5 + ), fructose and glucose were determined through a calibration curve and confirmed by

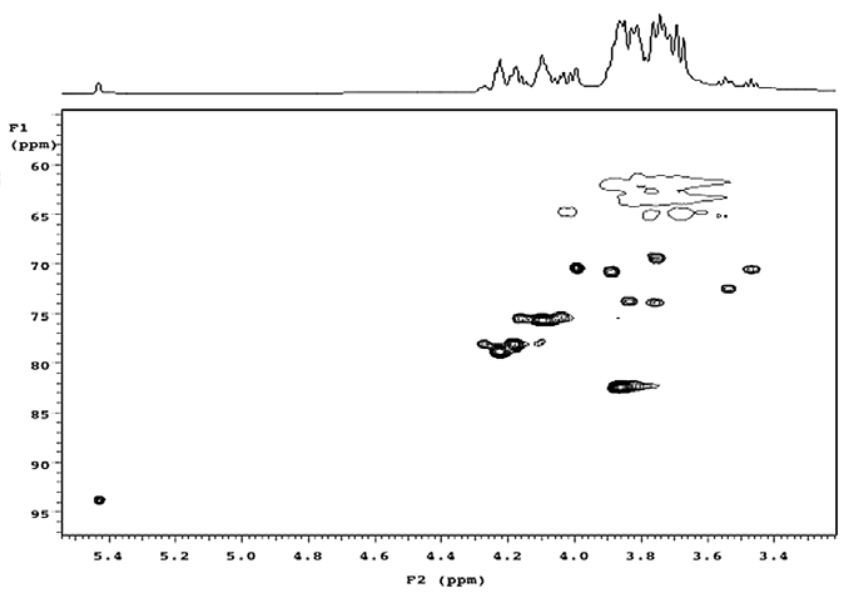

mass balance of the free fructose and glucose and as linked monomer in FOS.

Table 1 presents the concentration of FOS after direct atmospheric cold plasma treatment of the FOS solution and the relative changes observed after the treatment. The direct plasma treatment has not showed any significant change $(P<0.05)$ in the concentration of FOS and corroborated with the results obtained through NMR analysis. Tukey's test was carried out with the data and confirmed that the concentration of each degree of polymerisation was statistically similar at each processing time that was studied and to the control (untreated FOS solution).

Cold plasma treatment produces several different free radicals, anions and cations that can lead to polymerisation of several organic compounds (Song et al., 2013; Hazrati et al., 2014; Liu et al., 2014). No further polymerisation of FOS occurred during direct plasma treatment, because the concentration of the several degrees of FOS oligomers remained constant and no decrease in the concentration of fructose or glucose was observed, which would indicate polymerisation of the compounds.

The treatment with indirect cold air plasma also did not change significantly $(P<0.05)$ the concentration

Table 1 Concentration and relative changes of FOS, fructose and glucose $\left(\mathrm{g} \mathrm{L}^{-1}\right)$ after direct plasma processing

\begin{tabular}{|c|c|c|c|c|c|c|c|c|c|}
\hline \multirow[b]{2}{*}{ Component } & \multicolumn{5}{|c|}{ Concentration $\left(\mathrm{g} \mathrm{L}^{-1}\right)$} & \multicolumn{4}{|c|}{ Change in concentration $\left(\mathrm{g} \mathrm{L}^{-1}\right)$} \\
\hline & $0 \mathrm{~s}$ (initial) & $15 s$ & $30 \mathrm{~s}$ & $45 \mathrm{~s}$ & $60 \mathrm{~s}$ & $15 \mathrm{~s}$ & $30 \mathrm{~s}$ & $45 \mathrm{~s}$ & $60 \mathrm{~s}$ \\
\hline DP5+ & $3.3 \pm 0.1^{a}$ & $3.3 \pm 0.1^{\mathrm{a}}$ & $3.3 \pm 0.1^{\mathrm{a}}$ & $3.3 \pm 0.1^{\mathrm{a}}$ & $3.3 \pm 0.1^{\mathrm{a}}$ & 0.0 & 0.0 & 0.0 & 0.0 \\
\hline DP5 & $31.0 \pm 0.1^{\mathrm{b}}$ & $31.0 \pm 0.1^{\mathrm{b}}$ & $31.0 \pm 0.1^{\mathrm{b}}$ & $31.0 \pm 0.1^{\mathrm{b}}$ & $30.9 \pm 0.1^{b}$ & 0.0 & 0.0 & 0.0 & -0.1 \\
\hline DP4 & $14.2 \pm 0.1^{\mathrm{c}}$ & $14.2 \pm 0.1^{\mathrm{c}}$ & $14.3 \pm 0.1^{\mathrm{c}}$ & $14.3 \pm 0.1^{\mathrm{c}}$ & $14.3 \pm 0.1^{\mathrm{c}}$ & 0.0 & 0.1 & 0.0 & 0.1 \\
\hline DP3 & $14.2 \pm 0.1^{d}$ & $14.2 \pm 0.1^{\mathrm{d}}$ & $14.2 \pm 0.1^{\mathrm{d}}$ & $14.2 \pm 0.1^{d}$ & $14.2 \pm 0.1^{d}$ & 0.0 & 0.0 & 0.0 & 0.0 \\
\hline Glucose & $4.2 \pm 0.1^{\mathrm{e}}$ & $4.2 \pm 0.1^{\mathrm{e}}$ & $4.2 \pm 0.1^{\mathrm{e}}$ & $4.2 \pm 0.1^{\mathrm{e}}$ & $4.2 \pm 0.1^{\mathrm{e}}$ & 0.0 & 0.0 & 0.0 & 0.0 \\
\hline Fructose & $3.1 \pm 0.1^{f}$ & $3.1 \pm 0.1^{f}$ & $3.0 \pm 0.1^{f}$ & $3.0 \pm 0.1^{f}$ & $3.1 \pm 0.1^{f}$ & 0.0 & -0.1 & 0.0 & 0.1 \\
\hline
\end{tabular}

Figures with the same letters are not significantly different $(P<0.05)$. 
of FOS, glucose and fructose in the solution (Table 2). The indirect plasma treatment is usually less intense than the direct plasma treatment. The number of free radicals, anions and cations is lower, and the energy transferred from plasma to the treated solution is lower as well. The results obtained from indirect plasma treatment showed also that no depolymerisation or hydrolysis of FOS occurred. Similar to the results observed with direct plasma treatment, Tukey's test has confirmed that the concentration of each degree of polymerisation was statistically similar at each processing time that was tested and to the control.

These results are positive, because direct and indirect plasma treatment could be applied to liquids (milk, juices and others) containing FOS without compromising the concentration of FOS and thus its prebiotic potential.

Table 3 presents the concentration of FOS after high-pressure processing (HPP) and after ultrasonic treatment followed by HPP of the FOS solution. No significant change was observed in the concentration of FOS after the application of these processes $(P<0.05)$. The retention of FOS in HPP is related to the mechanical nature of this process and because no chemical species are usually produced during its application.
Depolymerisation of FOS was a concern because some studies showed that some polysaccharides hydrolyse when subjected to ultrasound application. Studies showed that high power low frequency ultrasound produces cavitation that are able to split macromolecules in a nonrandom way, producing a narrower mass distribution polysaccharide (Price, 1990). Cavitations produced by ultrasound application were able to reduce the average chain length of dextran, starch, xanthan and chitin (Szu et al., 1986; Lorimer et al., 1995; Takahashi et al., 1995; Berth et al., 1996; Portenlänger \& Heusinger, 1997).

The application of ultrasound prior to HPP, however, could lead to hydrolysis of FOS molecules because the cavitation produced in the aqueous solution generates free radicals that could theoretically attack the FOS molecules. The results showed the FOS solution maintained its characteristics and that this kind of molecules is not susceptible to hydrolysis by ultrasound. Tukey's test was carried out with the data and confirmed that the concentration of each degree of polymerisation was statistically similar to the control (untreated FOS solution).

Thermal processing of FOS, reported by several works (L'Homme et al., 2003a,b; Huebner et al., 2008; Courtin et al., 2009; Campos et al., 2016), showed a significant change in FOS content and high rates of

Table 2 Concentration and relative changes of FOS, fructose and glucose $\left(\mathrm{g} \mathrm{L}^{-1}\right)$ after indirect plasma processing

\begin{tabular}{|c|c|c|c|c|c|c|c|c|c|}
\hline \multirow[b]{2}{*}{ Component } & \multicolumn{5}{|c|}{ Concentration $\left(\mathrm{g} \mathrm{L}^{-1}\right)$} & \multicolumn{4}{|c|}{ Change in concentration $\left(\mathrm{g} \mathrm{L}^{-1}\right)$} \\
\hline & $0 \mathrm{~s}$ (initial) & $15 \mathrm{~s}$ & $30 \mathrm{~s}$ & $45 \mathrm{~s}$ & $60 \mathrm{~s}$ & $15 \mathrm{~s}$ & $30 \mathrm{~s}$ & $45 \mathrm{~s}$ & $60 \mathrm{~s}$ \\
\hline DP5+ & $3.3 \pm 0.1^{\mathrm{a}}$ & $3.3 \pm 0.1^{\mathrm{a}}$ & $3.3 \pm 0.1^{\mathrm{a}}$ & $3.3 \pm 0.1^{\mathrm{a}}$ & $3.3 \pm 0.1^{\mathrm{a}}$ & 0.0 & 0.0 & 0.0 & 0.0 \\
\hline DP5 & $31.0 \pm 0.1^{\mathrm{b}}$ & $31.1 \pm 0.1^{\mathrm{b}}$ & $31.0 \pm 0.1^{\mathrm{b}}$ & $31.0 \pm 0.1^{b}$ & $30.9 \pm 0.1^{b}$ & 0.1 & 0.0 & 0.0 & -0.1 \\
\hline DP4 & $14.2 \pm 0.1^{c}$ & $14.3 \pm 0.1^{\mathrm{c}}$ & $14.3 \pm 0.1^{c}$ & $14.2 \pm 0.1^{\mathrm{c}}$ & $14.3 \pm 0.1^{\mathrm{c}}$ & 0.1 & 0.0 & -0.1 & 0.1 \\
\hline DP3 & $14.2 \pm 0.1^{\mathrm{d}}$ & $14.2 \pm 0.1^{\mathrm{d}}$ & $14.2 \pm 0.1^{\mathrm{d}}$ & $14.2 \pm 0.1^{d}$ & $14.2 \pm 0.1^{\mathrm{d}}$ & 0.0 & 0.0 & 0.0 & 0.0 \\
\hline Glucose & $4.2 \pm 0.1^{\mathrm{e}}$ & $4.2 \pm 0.1^{\mathrm{e}}$ & $4.2 \pm 0.1^{\mathrm{e}}$ & $4.2 \pm 0.1^{\mathrm{e}}$ & $4.2 \pm 0.1^{\mathrm{e}}$ & 0.0 & 0.0 & 0.0 & 0.0 \\
\hline Fructose & $3.1 \pm 0.1^{f}$ & $3.0 \pm 0.1^{f}$ & $3.0 \pm 0.1^{f}$ & $3.0 \pm 0.1^{f}$ & $3.1 \pm 0.1^{f}$ & -0.1 & 0.0 & 0.0 & 0.1 \\
\hline
\end{tabular}

Figures with the same letters are not significantly different $(P<0.05)$.

Table 3 Concentration and relative changes of FOS, fructose and glucose $\left(\mathrm{g} \mathrm{L}^{-1}\right)$ after treatments with HPP and with ultrasound application followed by HPP

\begin{tabular}{|c|c|c|c|c|c|c|c|}
\hline \multirow[b]{2}{*}{ Component } & \multicolumn{4}{|c|}{ Concentration $\left(\mathrm{g} \mathrm{L}^{-1}\right)$} & \multicolumn{3}{|c|}{ Change in concentration $\left(\mathrm{g} \mathrm{L}^{-1}\right)$} \\
\hline & Control & HPP & $\begin{array}{l}\text { US }\left(600 \mathrm{~W} \mathrm{~L}^{-1}\right) \\
+ \text { HPP }\end{array}$ & $\begin{array}{l}\text { US }\left(1200 \mathrm{~W} \mathrm{~L}^{-1}\right) \\
+\mathrm{HPP}\end{array}$ & HPP & $\begin{array}{l}\text { US }\left(600 \mathrm{~W} \mathrm{~L}^{-1}\right) \\
+ \text { HPP }\end{array}$ & $\begin{array}{l}\text { US }\left(1200 \mathrm{~W} \mathrm{~L}^{-1}\right) \\
+\mathrm{HPP}\end{array}$ \\
\hline DP5+ & $3.3 \pm 0.1^{\mathrm{a}}$ & $3.3 \pm 0.1^{\mathrm{a}}$ & $3.3 \pm 0.1^{\mathrm{a}}$ & $3.3 \pm 0.1^{\mathrm{a}}$ & 0.0 & 0.0 & 0.0 \\
\hline DP5 & $31.0 \pm 0.1^{b}$ & $31.1 \pm 0.1^{\mathrm{b}}$ & $31.0 \pm 0.1^{b}$ & $31.0 \pm 0.1^{\mathrm{b}}$ & 0.1 & 0.0 & 0.0 \\
\hline DP4 & $14.2 \pm 0.1^{\mathrm{c}}$ & $14.2 \pm 0.1^{\mathrm{c}}$ & $14.3 \pm 0.1^{\mathrm{c}}$ & $14.3 \pm 0.1^{\mathrm{c}}$ & 0.0 & 0.1 & 0.1 \\
\hline DP3 & $14.2 \pm 0.1^{\mathrm{d}}$ & $14.2 \pm 0.1^{\mathrm{d}}$ & $14.3 \pm 0.1^{\mathrm{d}}$ & $14.3 \pm 0.1^{d}$ & 0.0 & 0.1 & 0.1 \\
\hline Glucose & $4.2 \pm 0.1^{\mathrm{e}}$ & $4.2 \pm 0.1^{\mathrm{e}}$ & $4.2 \pm 0.1^{\mathrm{e}}$ & $4.2 \pm 0.1^{\mathrm{e}}$ & 0.0 & 0.0 & 0.0 \\
\hline Fructose & $3.1 \pm 0.1^{f}$ & $2.9 \pm 0.1^{f}$ & $2.9 \pm 0.1^{f}$ & $2.9 \pm 0.1^{f}$ & -0.2 & -0.2 & -0.2 \\
\hline
\end{tabular}

Figures with the same letters are not significantly different $(P<0.05)$. 
hydrolysis. Courtin et al. (2009) reported losses up to $65 \%$ of FOS in model solution after $15 \mathrm{~min}$ of processing at $100{ }^{\circ} \mathrm{C}$. According to the authors, FOS were very sensitive to hydrolysis during thermal processing and much more sensitive than AXOS (arabinoxylooligosaccharides) and XOS (xylooligosaccharides). It was found that the hydrolysis of FOS increased with increasing temperature. The results reported by Vega \& Zuniga-Hansen (2015) has shown a low retention of FOS $(<80 \%)$ after thermal processing in a citrate buffer solution and also in orange and tomato juice. However, their results differ from the results of Courtin et al. (2009) regarding the influence of the temperature, because it was found that the hydrolysis of FOS decreased with increasing temperature. Studies carried out with blanching of yacon showed that blanching $\left(50-80{ }^{\circ} \mathrm{C}\right)$ has caused the hydrolysis of FOS, reducing the contents of FOS by 13 to $32 \%$ depending on the temperature that was applied (Campos et al., 2016).

The insignificant changes found after the different treatments and exposures indicate that these nonthermal processes did not affect the FOS concentration. The stability of these compounds is an advantage because the nonthermal sterilisation processes represents rapid, efficient and reliable alternatives to improve the quality of food.

\section{Conclusions}

Atmospheric cold plasma (direct or indirect application), high-pressure processing (HPP) and ultrasonic treatment followed by HPP did not change significantly the concentration of FOS solution and have not hydrolysed the FOS molecules. The results indicate that these nonthermal processes may be applied to liquids containing FOS in its formulation, without compromising its concentration and thus prebiotic potential. The nonthermal processes studied herein resulted in a much higher retention of FOS than the traditional thermal processing.

\section{Acknowledgments}

The authors thank CNPq and FUNCAP for the financial support and for the award of scholarship, to Healy Group for the FOS sample and to HPP Tolling Ltd (Dublin, Ireland) for enabling the use of the HPP equipment.

\section{References}

Aguilar, R., Ramírez, J.A., Garrote, G. \& Vásquez, M. (2002). Kinetic study of the acid hydrolysis of sugar cane bagasse. Journal of Food Engineering, 55, 309-318.

Alles, M.S., Roos, N.M.D., Bakx, J.C., Lisdonk, E.V.D., Zock, P.L. \& Hautvast, J.G.A.J. (1999). Consumption of fructooligosaccharides does not favorably affect blood glucose and serum lipid concentrations in patients with type 2 diabetes. American Journal of Clinical Nutrition, 69, 64-69.

Al-Sheraji, S.H., Ismail, A., Manap, M.Y., Mustafa, S., Yusof, R.M. \& Hassan, F.A. (2013). Prebiotics as functional foods: a review. Journal of Functional Foods, 5, 1542-1553.

Berth, G., Dautzenberg, H., Christensen, B.E., Harding, S.E., Rother, G. \& Smidosrod, O. (1996). Static light scattering studies on xanthan in aqueous solutions. Macromolecules, 29, 34913498.

Breithaupt, D.E. (2001). Determination of folic acid by ion-pair RPHPLC in vitamin-fortified fruit juices after solid-phase extraction. Food Chemistry, 74, 521-525.

Campos, D., Aguilar-Galvez, A. \& Pedreschi, R. (2016). Stability of fructooligosaccharides, sugars and colour of yacon (Smallanthus sonchifolius) roots during blanching and drying. International Journal of Food Science and Technology, 51, 1958-1966.

Carabin, I.G. \& Flamm, W.G. (1999). Evaluation of safety of inulin and oligofructose as dietary fiber. Regulatory Toxicology and Pharmacology, 30, 268-282.

Charalampopoulos, D. \& Rastall, R.A. (2012). Prebiotics in foods. Current Opinions in Biotechnology, 23, 187-191.

Chen, J., Zheng, X., Dong, J., Chen, Y. \& Tian, J. (2015). Optimization of effective high hydrostatic pressure treatment of Bacillus subtilis in Hami melon juice. LWT - Food Science and Technology, 60, 1168-1173.

Costa, M.G.M., Fonteles, T.V., Jesus, A.L.T. et al. (2011). Highintensity ultrasound processing of pineapple juice. Food and Bioprocess Technology, 6, 997-1006.

Courtin, C.M., Swennen, K., Verjans, P. \& Delcour, J.A. (2009). Heat and $\mathrm{pH}$ stability of prebiotic arabinoxylooligosaccharides, xylooligosaccharides and fructooligosaccharides. Food Chemistry, 112, 831-837.

Denes, F. (2004). Macromolecular plasma-chemistry: an emerging field of polymer science. Progress in Polymer Science, 29, 815-885.

Evelyn \& Silva, F.V.M. (2016). High pressure processing pretreatment enhanced the thermosonication inactivation of Alicyclobacillus acidoterrestris spores in orange juice. Food Control, 62, 365372.

Fernandes, F.A.N., Rodrigues, S., Law, C.L. \& Mujumdar, A.S. (2010). Drying of exotic tropical fruits: a comprehensive review. Food and Bioprocess Technology, 4, 163-185.

Garcia-Noguera, J., Oliveira, F.I.P., Gallão, M.I., Weller, C.L., Rodrigues, S. \& Fernandes, F.A.N. (2010). Ultrasound-assisted osmotic dehydration of strawberries: effect of pretreatment time and ultrasonic frequency. Drying Technology, 28, 294-303.

Hazrati, H.D., Whittle, J.D. \& Vasilev, K. (2014). A mechanistic study of the plasma polymerization of ethanol. Plasma Processes and Polymers, 11, 149-157.

Huebner, J., Wehling, R.L., Parkhurst, A. \& Hutkins, R.W. (2008). Effect of processing conditions on the prebiotic activity of commercial prebiotics. International Dairy Journal, 18, 287-293.

L'Homme, C., Arbelot, M., Puigserver, A. \& Biagini, A. (2003a). Kinetics of hydrolysis of fructooligosaccharides in mineral-buffered aqueous solutions: influence of $\mathrm{pH}$ and temperature. Journal of Agricultural and Food Chemistry, 51, 224-228.

L'Homme, C., Puigserver, A. \& Biagini, A. (2003b). Effect of foodprocessing on the degradation of fructooligosaccharides in fruit. Food Chemistry, 82, 533-537.

Liu, D., Zhang, Y., Sun, X. \& Chang, P.R. (2014). Recent advances in bio-sourced polymeric carbohydrate/nanotube composites. Journal of Applied Polymer Science, 131, 40359. doi:10.1002/app.40359.

Lorimer, J.P., Mason, T.J., Cuthbert, T.C. \& Brookfield, E.A. (1995). Effect of ultrasound on the degradation of aqueous native dextran. Ultrasonics sonochemistry, 2, S55-S57.

Luckow, T., Sheehan, V., Fitzgerald, G. \& Delahunty, C. (2006). Exposure, health information and flavour-masking strategies for improving the sensory quality of probiotic juice. Appetite, 47, 315323 . 
Macfarlane, S., Macfarlane, G.T. \& Cummings, J.H. (2006). Prebiotic in the gastrointestinal tract. Alimentary Pharmacology and Therapeutics, 24, 701-714.

Morris, C. \& Morris, G.A. (2012). The effect of inulin and fructooligosaccharide supplementation on the textural, rheological and sensory properties of bread and their role in weight management: a review. Food Chemistry, 133, 237-248.

Perera, N., Gamage, T.V., Wakeling, L., Gamalath, G.G.S. \& Versteeg, C. (2009). Colour of apples high pressure processed in pineapple juice. Innovative Food Science and Emerging Technologies, 11, 39-46.

Portenlänger, G. \& Heusinger, H. (1997). The influence of frequency on the mechanical and radical effects for the ultrasonic degradation of dextranes. Ultrasonics sonochemistry, 4, 127-130.

Price, G.J. (1990). The use of ultrasound for the controlled degradation of polymer solutions. In: Advances in Sonochemistry (edited by Mason T.J.). Pp. 231-287. London: JAI Press.

Ranadheera, R.D.C.S., Baines, S.K. \& Adams, M.C. (2010). Importance of food in probiotic efficacy. Food Research International, 43, $1-7$.

Rastall, R.A. (2010). Functional oligosaccharides: application and manufacture. Annual Review of Food Science and Technology, 1, 305-339.

Renuka, B., Kulkarni, S.G., Vijayanand, P. \& Prapulla, S.G. (2009). Fructooligosaccharide fortification of selected fruit juice beverages: effect on the quality characteristics. LWT - Food Science and Technology, 42, 1031-1033.

Saad, N., Delattre, C., Urdaci, M., Schmitter, J.M. \& Bressollier, P. (2013). An overview of the last advances in probiotic and prebiotic field. LWT - Food Science and Technology, 50, 1-16.
Segat, A., Misra, N.N., Cullen, P.J. \& Innocente, N. (2015). Atmospheric pressure cold plasma (ACP) treatment of whey protein isolate model solution. Innovative Food Science \& Emerging Technologies, 29, 247-254.

Song, Z., Tang, J., Li, J. \& Xiao, H. (2013). Plasma-induced polymerization for enhancing paper hydrophobicity. Carbohydrate polymers, 92, 928-933.

Szu, S.C., Zon, G., Schneerson, R. \& Robbins, J.B. (1986). Ultrasonic irradiation of bacterial polysaccharides. Characterization of the depolymerized products and some applications of the process. Carbohydrate Research, 152, 7-20.

Takahashi, Y., Miki, F. \& Nagase, K. (1995). Effect of sonolysis on acid degradation of chitin to form oligosaccharides. Bulletin of the Chemical Society of Japan, 68, 1851-1857.

Tomomatsu, H. (1994). Health effects of oligosaccharides. Food Technology, 48, 61-65.

Uckoo, R.M., Jayaprakasha, G.K., Somerville, J.A., Balasubramaniam, V.M., Pinarte, M. \& Patil, B.S. (2013). High pressure processing controls microbial growth and minimally alters the levels of health promoting compounds in grapefruit (Citrus paradisi Macfad) juice. Innovative Food Science \& Emerging Technologies, 18, 7-14.

Vega, R. \& Zuniga-Hansen, M.E. (2015). The effect of processing conditions on the stability of fructooligosaccharides in acidic food products. Food Chemistry, 173, 784-789.

Yun, J.W. (1996). Fructooligosaccharides occurrence, preparation and application. Enzyme Microbiology Technology, 19, 107-117.

Ziuzina, D., Han, L., Cullen, P.J. \& Bourke, P. (2015). Cold plasma inactivation of internalised bacteria and biofilms for Salmonella enterica serovar Typhimurium, Listeria monocytogenes and Escherichia coli. International Journal of Food Microbiology, 210, 53-61. 